\title{
La palabra como «don explosivo»: ciencia, experimentación y ars poetica en Amanda Berenguer
}

\section{Una constelación propia}

Mi biografía es una sucesión de acontecimientos con el lenguaje. Por eso voy siguiendo sus pasos. Y no tengo más. A. Berenguer, El monstruo incesante ${ }^{1}$

Una doble constatación preliminar señala que la literatura uruguaya de los siglos XX y XXI es pródiga en obras particularmente originales y renovadoras, y que, dentro de este panorama de excepción, un lugar privilegiado lo ocupa la poesía escrita por mujeres. Para probarlo basta citar los nombres de Idea Vilariño, Marosa di Giorgio, Ida Vitale, Circe Maia, o bien el de Amanda Berenguer, autora de una poética camaleónica, en constante transformación, que quisiéramos examinar en estas páginas.

En una carrera desarrollada a lo largo de sesenta años, Amanda Berenguer (Montevideo, 1921-2009) escribió unos veinte libros de poemas donde se advierten muchas de las principales inquietudes y vías de experimentación que recorren la poesía latinoamericana a partir de la segunda mitad del siglo pasado. Las historias de la literatura ubican sus inicios en el contexto de la llamada Generación del 45 o Generación Crítica, de la que también formaron parte su esposo, el escritor y profesor José Pedro Díaz, junto a Carlos Maggi, Ángel Rama, Ida Vitale, Idea Vilariño y Mario Benedetti, entre otros intelectuales. ${ }^{2}$

Una mirada de conjunto a la obra de Berenguer permite apreciar la variedad de tonos e intereses que la atraviesan. Entre sus páginas desfilan la poesía de corte filosófico o meditativo, el objetivismo volcado al paisaje y el imaginario vegetal, las dinámicas del erotismo, el compromiso político y el crudo examen de las mitologías occidentales y precolombinas de la muerte. En todos los casos, la dicción resulta certera, escueta y modulada por una voz femenina que interroga lúcidamente el presente personal, familiar y social.

1 Amanda Berenguer: El monstruo incesante (expedición de caza). Montevideo: Arca 1990, p. 152. 2 María Inés Silva Vila: Cuarenta y cinco por uno. Montevideo: Fin de Siglo 1993.

María Lucía Puppo, Universidad Católica Argentina, Buenos Aires/CONICET

Ә Open Access. (C) 2021 María Lucía Puppo, published by De Gruyter. (๔) BY-Nc-ND This work is licensed under the Creative Commons Attribution-NonCommercial-NoDerivatives 4.0 International License. 
Carina Blixen ${ }^{3}$ ha señalado que cada libro de Amanda Berenguer está pensado como una totalidad, así como su obra entera resulta una unidad sometida a diversas metamorfosis. Por el mismo motivo, Rafael Courtoisie ${ }^{4}$ observa que la poesía de Berenguer se ajusta a la imagen de la constelación. Justamente bajo el título Constelación del navío. Poesía 1950-2002 fue reunida en Montevideo, en una cuidada edición, la mayor parte de su obra publicada e inédita hasta entonces. ${ }^{5}$

Tras haber dedicado estudios a diversos problemas, aspectos y procedimientos que resultan centrales en la obra de Amanda Berenguer, en este trabajo ofreceremos un acercamiento a la poética que anima sus textos, entendida esta como el núcleo íntimo o motor secreto donde se origina su peculiar energía expansiva. Para ello recurriremos a algunos poemas claves, que ponen en escena un giro autorreferencial de la escritura, y a una serie de escritos metapoéticos que la propia autora reunió en el volumen El monstruo incesante (expedición de caza), editado por Arca en $1990 .^{6}$

Observadora atenta del mundo, del lenguaje y de sí misma, la poeta uruguaya reflexionó sobre su quehacer en numerosas instancias que fue registrando a lo largo de sus ochenta y nueve años de vida. Proponemos adentrarnos en su ars poetica a partir de la consideración de tres grandes ejes o preocupaciones que la estructuran: el espacio, la visualidad y la fuerza comunicativa del poema.

\section{Cosmos, topologías y fractales}

La supuesta curiosidad femenina dejó de ser un tópico patriarcal una vez que las escritoras lo hicieron suyo y revirtieron sus connotaciones peyorativas. Guiada por la curiosidad y fascinada por los modelos y las leyes de la ciencia, Amanda

\footnotetext{
3 Carina Blixen: «Amanda Berenguer: Poeta en metamorfosis». In: Heber Raviolo y Pablo Rocca (eds.): Historia de la Literatura Uruguaya contemporánea. Tomo II: Una literatura en movimiento. Montevideo: Banda Oriental 1997.

4 Rafael Courtoisie: «Navegar es necesario: Suma poética de Amanda Berenguer». In: El País Cultural 706, 16 de mayo de 2003. http://letras-uruguay.espaciolatino.com/berenguer/bio.html [Consultado el 15 de junio 2020].

5 En esta edición quedaron afuera tres poemarios de juventud, publicados antes de 1946, y dos series breves: Las mil y una preguntas y propicios contextos (2005) y Casas donde viven criaturas del lenguaje y el diccionario (2005). De aparición póstuma, La cuidadora del fuego (2010) presenta un valioso conjunto de poemas sueltos compilados por Roberto Echavarren. Una primera edición de Poesías. 1949-1979 había visto la luz en Buenos Aires, en 1980, bajo el sello Calicanto. 6 Esta compilación reúne una serie de notas y entrevistas a la autora, así como el ensayo «Dialéctica de la invención», publicado originariamente en Materia prima (1966) y una «Autobiografìa» redactada por Berenguer en 1990.
} 
Berenguer desplegó en su poesía una «infatigable capacidad de investigación» ${ }^{7}$ que le permitió ir «al encuentro de territorios que pocos han osado invadir». ${ }^{8}$ Esto se advierte especialmente en Quehaceres e invenciones (1963) y Materia prima (1966), dos volúmenes que abrevan en el imaginario científico, ya sea en su vertiente astronómica, matemática o de ciencia ficción. En el segundo se incluye el poema extenso «Las nubes de Magallanes», sintagma que hace referencia a dos galaxias enanas visibles desde nuestra Vía Láctea. En este texto complejo, cargado de resonancias míticas e históricas, las estrellas resultan imágenes nucleares, disparadores capaces de lanzar el poema hacia interrogantes de orden filosófico, político, lingüístico o existencial.

Explica la autora en su «Autobiografía»:

Sigo asombrándome ante el monstruo incesante del universo. Ante la realidad, por ej. ante esta mesa: esta danza loca de electrones. El conocimiento científico y sus aparatos o instrumentos: microscopios, telescopios, helicópteros, jets, satélites artificiales, televisores, computadoras, etc., etc., me producen vértigo, y pienso que esas palabras que los nombran, y con las que convivimos, tienen que ser elementos de poesía. Hay que apresar su presencia de recién llegadas al idioma. Aunque a veces me pregunto si ese lenguaje técnico-científico, con su enorme carga de misterio, no es, en sí mismo, una nueva poesía. ${ }^{9}$

De la atracción por lo novedoso y las formas espaciales surge también la predilección de Berenguer por la cinta de Moebius, objeto al que recurrió como modelo eidético y al que llegó a calificar como su «emblema». ${ }^{10}$ Décadas más tarde, su interés por la topología regresa en un poemario tardío, La botella verde, Analysis situs (1995). En este libro el punto de partida es la observación de una botella de Klein, ese objeto extraño, paradojal, donde no es posible discernir un interior ni un exterior. Como cumpliendo un probable sueño de Alicia o una aventura de Gulliver, la hablante poética habita dentro de la botella polimorfa, que puede volverse síntesis del aislamiento a pesar de estar poblada de familiares y amigos. Lugar físico, filtro para la mirada y puesta en escena de los vínculos humanos, la botella verde deviene finalmente clave poética, emblema de una estética relacional. ${ }^{11}$

7 Hugo García Robles: «Constancia de la razón poética». In: Cuadernos Hispanoamericanos 632 (2003), p. 20.

8 Mario Benedetti citado en Clemente Padín: «V+V. Lo Verbal y lo Visual en el arte uruguayo. Segunda Parte». In: Escáner Cultural. El Mundo del Arte 20 (2000)._http://www.escaner.cl/escaner20/acorreo.html [Consultado el 16 de junio 2020].

9 Amanda Berenguer: El monstruo, p. 152.

10 Amanda Berenguer: La cuidadora del fuego. Montevideo: La Flauta Mágica 2010, p. 155.

11 María Lucía Puppo: «Dos raras de la poesía uruguaya: Amanda Berenguer y Marosa di Giorgio». In: Ínsula. Revista de Letras y Ciencias Humanas 853-854 (2018). 
En este poemario hallamos la siguiente composición:

(la carta)

This is my letter to the world,

That never wrote to me-

Emily Dickinson

escribo una carta infinita

en la pared ambigua

del recipiente que me contiene

unas veces adentro

otras veces afuera

sin levantar el bolígrafo

escribo una carta infinita. ${ }^{12}$

$\mathrm{Al}$ retomar las palabras del epígrafe de Emily Dickinson, el poema se autopostula como una carta dirigida al mundo. Su estructura se vuelve circular como la cinta descubierta por Moebius y la botella que deslumbró a Klein, en las que no es posible discernir un comienzo ni un fin. Mensaje que parte y deambula a través del tiempo y el espacio, resulta una versión contemporánea de la antigua «botella al mar». ${ }^{13}$ Se trata, entonces, de la misma imagen que eligió Paul Celan en 1958 para referirse al poema en tanto «manifestación del lenguaje y por tanto esencialmente dialógico». ${ }^{14}$

¿El poema es un instante, una estación, una ola en el mar de la poesía, que sería entonces «infinita»? Lo cierto es que en su dinámica confluyen un movimiento hacia adentro y otro hacia afuera, porque la poesía, como se dice en otro poema de la botella, es «forma solipsista pero enajenada», ${ }^{15}$ nunca esfera que vuelve sobre su propio eje. ${ }^{16}$

Al mismo tiempo casa del lenguaje y ventana que mira al mundo, el poema-botella no resulta inmune al olvido y el «accidente». ${ }^{17}$ Lejos de la panacea

12 Amanda Berenguer: Constelación del Navío. Poesía 1950-2002. Montevideo: H Editores 2002, p. 613.

13 Ibid., p. 636.

14 Paul Celan: Obras completas. Madrid: Trotta 2000, p. 498.

15 Amanda Berenguer: Constelación, p. 639.

16 En este punto, Berenguer coincide con la caracterización que brinda Derrida del poema como erizo: «El poema puede hacerse un ovillo pero es para volver otra vez sus signos agudos hacia afuera. Puede por cierto reflejar la lengua o decir la poesía pero no se refiere nunca a sí, no se mueve nunca por sí mismo como esas máquinas portadoras de muerte. Su acontecimiento siempre interrumpe o desvía el saber absoluto, el ser próximo a sí en la autotelia» (Jacques Derrida: «Che cos `è la poesia?». In: Poesia I (11 de noviembre de 1988). Trad, de J. S. Perednik).

17 Amanda Berenguer: Constelación, p. 641. 
que garantizaría la plenitud del significado y la comprensión perfecta, los versos cortantes de Berenguer nos indican que la poesía de nuestros días tiene que ver con el fragmento, la repetición, la dilación infinita y el diálogo trunco. ${ }^{18}$

Vale la pena considerar ahora un poema anterior, perteneciente a la serie «Trazo y derivados» (1976-1978):

\author{
TRAZO \\ ¿Por qué esta arena de desierto \\ invadiendo la hoja donde escribo? \\ Trazo una línea honda y larga \\ sobre la duna \\ pero el viento la borra \\ sigo la línea honda y larga \\ otra vez \\ y de pronto comprendo \\ donde está la línea está el viento \\ donde está el viento no hay nada. ${ }^{19}$
}

En este caso, la escena de escritura no preserva la asepsia del espacio cerrado. Los sintagmas aluden a la vastedad de la playa en un día ventoso, revelando la dificultad de la escriba. De nuevo se presenta una continuidad espacial, que esta vez opera a través de la metonimia hoja-duna. Resulta difícil trazar una línea en una y otra superficie, pero ese fracaso repetido permite asomarse a una revelación: donde hay escritura hay falta, donde ocurre algo se aloja también la ausencia.

Mediante pliegues y repliegues del habla y referencias a las paradojas que desafían la lógica aristotélica, la escritura de Berenguer apunta a «la búsqueda de un lugar de enunciación tensionado entre un adentro y un afuera que no parece resolverse nunca». ${ }^{20} \mathrm{Su}$ poética espacial se relaciona, ante todo, con las elecciones temáticas y los procedimientos compositivos que se integran en el

18 María Lucía Puppo: «Poesía «concéntrica y excéntrica〉: notas para leer La botella verde (1995) de Amanda Berenguer». In: Germán Prósperi (ed.): Debates actuales del hispanismo: balances y desafíos críticos: Actas del X Congreso Argentino de Hispanistas, p. 530-539. Santa Fe: Universidad Nacional del Litoral/Facultad de Humanidades y Ciencias 2016.

19 Amanda Berenguer: Constelación, p. 365.

20 Sebastián Urli: «Entre el grajo y la lengua: Berenguer y los límites del sujeto». In: Revista Iberamericana 258 (2017), p. 136. 
dinamismo del imaginario, en un incesante viaje de ida y vuelta de la macro a la microscópica. Las distintas piezas que integran los poemas (estrofas, versos, epígrafes) suelen conformar un diseño que las grandes estructuras (libros, poemas largos) reproducen en otra escala. Al llamar la atención sobre la parcialidad de la mirada y la multiplicación de los puntos de vista, la exploración poética del espacio permite pensar y problematizar nociones como distancia, exterioridad, límite e infinito. Esta complejidad vislumbrada en los textos parece hacer estallar la idea de un espacio fijo y unívoco, para reformularse mejor en la proliferación del rizoma y la fractalidad de los cristales.

\section{En el principio era el ojo}

La visualidad es el segundo eje en torno al cual se organiza la poética de Amanda Berenguer. La importancia de la visión y la construcción cultural de la mirada se permean en todos sus escritos metatextuales, como ocurre en este pasaje de su «Autobiografía»: «El monstruo incesante nos rodea o nos invade o nos transforma o nos ciega o nos da rayos o palabras o células o genes inmortales. Todo el universo, móvil vehemente, cabe en el vocablo que lo nombra». ${ }^{21}$

Para la autora uruguaya, la percepción sensorial descansa mayormente sobre «los totales ojos» que dimensionan los cambios del color, la luz y el movimiento. ${ }^{22}$ Son estos órganos los primeros responsables de atrapar la realidad; luego será la palabra poética la encargada de hallar una forma para representarla. Así surge la metáfora de la caza:

\section{LA MIRA}

alcanza cazador

$$
\begin{gathered}
\text { ahí } \\
\text { la presa } \\
\text { el concéntrico } \\
\text { blanco } \\
\text { radiante }
\end{gathered}
$$

alcanza el corazón

el círculo

el espectro

el veredicto

21 Amanda Berenguer: El monstruo, p. 156.

22 Amanda Berenguer: Constelación, p. 99. 
la batalla ha comenzado

persigue el objetivo

ausculta el viento

detrás de ti se levanta

un foco

oscilando su implacable destello. ${ }^{23}$

Este poema de El tigre alfabetario (1979) pone en escena la pesquisa y «la batalla» que resulta la escritura para una mujer que la concibe, ante todo, como un ejercicio de «intensidad» y experimentación, una búsqueda incesante de la «apertura de las formas». ${ }^{24}$ Proponemos leerlo en una misma serie con una composición de La Dama de Elche (1987). Esto nos permitirá apreciar que, en la obra de Berenguer como en la de muchas otras poetas contemporáneas, la indagación acerca de la propia escritura converge, mediante el imaginario visual, en el autorretrato:

\section{a Luis Bravo}

(EL VIDRIO NEGRO)

el cono de la lámpara me pone a foco

más cerca

más nítida

me veo y me ven

la imagen con fantasma ajustará sus círculos

y no sé si cubrirla ya con un paño de lágrimas

el recuadro de una silla enmarca la lluvia

sobre el vidrio negro

el árbol en lo oscuro

inclina del otro lado sobre mi hombro

su brillo cubierto de hilos

-la ventana es un ojo

un dragón de tinta-

esa torcaza colgada a mis espaldas

proyecta una espiral amarilla

y mostacillas de fósforo le queman las alas

-se repite-

el vidrio negro nos envuelve malignamente:

23 Ibid., p. 407.

24 Amanda Berenguer: El monstruo, p. 16, 63. 
la ventana es una célula encapuchada una mirada fotográfica un revólver

el cono de la lámpara me pone a foco está sentada vestida de rojo escribiendo mira de vez en cuando la ventana le apuntan: la lluvia sobre el vidrio negro

es un blanco perfecto ${ }^{25}$

Oscilando entre la vaguedad y una notable precisión verbal, el poema recurre a una escenografía cinematográfica. El lenguaje da cuenta de los movimientos de la mirada como una cámara que se acerca y se aleja, ya sea que enfoque a la protagonista o al decorado. La iluminación juega un rol fundamental («el cono de la lámpara«, «lo oscuro», «su brillo»), en tanto que el lente de la cámara se asocia al «vidrio negro» que posibilita una imagen poco nítida, «con fantasma».

La composición juega con la idea de encuadre y la posibilidad de registrar el momento de un rodaje. Afuera se describen imágenes en movimiento, hasta que el espacio cerrado de la habitación se superpone -o se perpetúa sin solución de continuidad - con el paisaje natural del exterior. El poema resulta de ese modo una cinta de Moebius donde la ventana funciona como un falso umbral entre dos ámbitos que, a su vez, son traspasados por «una mirada fotográfica» que acecha del otro lado del vidrio. La soledad de la protagonista en medio del juego de luces y la sucesión de espacios recuerda, por momentos, los cuadros de Edward Hopper.

En cuanto al autorretrato en sí, observamos que se construye en primera persona hasta los cinco versos finales, donde se impone la tercera. Entonces la hablante se ve y se dice a sí misma desde afuera, a la distancia, «sentada», «escribiendo», «vestida de rojo». . . Nos preguntamos si la poeta de fin del siglo XX evoca de manera conciente el famoso atuendo con que Delmira Agustini escandalizaba a sus contemporáneos; por lo pronto, en el poema las une a ambas, además del género, de un color y de la tarea de escriba, el hecho de constituirse como «un blanco perfecto». ${ }^{26}$ De ese modo la escritura femenina deviene un ejercicio de ver y dejarse ver, mostrar y mostrarse en un gesto de extrema exposición y vulnerabilidad. La poesía resulta, por consiguiente, una larga sesión de Blow

25 Ibid., p. 517.

26 El sintagma bien podría ser una alusión a la trágica muerte de Agustini, sobre cuya obra y figura Berenguer volvió en diferentes proyectos escriturales y editoriales a lo largo de su vida. 
up donde, como ocurre en la película de Antonioni, la ampliación de la imagen al mismo tiempo denuncia y replica la detonación de un arma. ${ }^{27}$

La poética de Amanda Berenguer propone una auténtica indagación acerca de los problemas relativos a la visión y sus tecnologías: el espejo, el lente de aumento, la fotografía, el cine. La exploración de diferentes dimensiones de la visualidad ocurre en el plano lingüístico pero también a través de los elementos icónicos que contribuyen al diseño del objeto libro. ${ }^{28}$ Por cuestiones de espacio nos limitaremos a mencionar aquí los juegos con la tipografía y los collages especialmente creados por la poeta montevideana para que fueran portadas de sus libros Identidad de ciertas frutas (1983), La botella verde (1995) y La estranguladora (1998), así como la inclusión de ilustraciones en el primer volumen mencionado: todos estos recursos establecen un peculiar diálogo intersemiótico que tensiona y problematiza la relación entre palabra e imagen. ${ }^{29}$

Toda referencia a la visualidad en la poesía de Berenguer exige además tomar en consideración Composición de lugar (1976), el poemario que lleva más lejos la experimentación y confirma a la autora como referente insoslayable de la neovanguardia latinoamericana. Se trata de un volumen que, en estrecha similitud con las distintas vistas de la Catedral de Rouen pintadas por Monet, ofrece diecinueve "ponientes sobre el mar» de los que, a su vez, se ofrecen tres versiones. Si en ciertas oportunidades el juego entre los valores gráficos del signo y del espacio en blanco alcanza el minimalismo del acróstico, el recurso a la repetición y la variación favorece la puesta en práctica de una original teoría de la "poesía cinética» que la autora había comenzado a desarrollar más de una década antes. ${ }^{30}$

Teniendo en mente los móviles de Calder y el arte cinético de Le Parc, en la tradición del «Coup de dés» mallarmeano, Berenguer buscó romper los moldes fijos del poema y desarticular la lectura lineal, con el fin de incorporar las variables del tiempo y el movimiento a la escritura.

27 María Lucía Puppo: «Entre la mirada fotográfica y la imagen fantasma: tres autorretratos de Amanda Berenguer». In: Perífrasis: Revista de Literatura, Teoría y Crítica 18 (2018), p. 65-79.

28 En los años cuarenta, Berenguer y su esposo José Pedro Díaz fundaron la editorial La Galatea, que funcionaba en su casa. Posiblemente debido a esa experiencia editorial de juventud, la poeta manifestó siempre un cuidado especial por el aspecto visual de sus poemas y sus libros.

29 María Lucía Puppo: «Contra el fondo negro: autofiguración y poética en dos collages de Amanda Berenguer». In: Actas de las I Jornadas Interdisciplinarias sobre Estudios de Género y Estudios Visuales «La producción visual de la sexualidad». Mar del Plata: Facultad de Humanidades/Universidad de Mar del Plata 2014. CD Rom.

30 María Lucía Puppo: «Teoría y práctica de la poesía cinética en Composición de lugar (1976) de Amanda Berenguer». In: LETRAS: Revista de la Facultad de Filosofía y Letras de la Pontificia Universidad Católica Argentina 69-70 (2014), p. 79-100. 


\section{Comunicar: maniobrar con un «don explosivo»}

Para Amanda Berenguer el poema es impensable sin el otro, o sea, sin el receptor o la receptora que habrá de llegar a su encuentro. Así lo declaraba en una conversación con Hilia Moreira:

[. . . ] todo escritor trabaja en una isla desierta. Siempre se está solo frente a la página en blanco. Pero la necesidad de objetivarse, de crear algo exterior a uno, es precisamente la necesidad de comunicarse. El objeto creado queda enfrentado al autor que se reconoce en él y se convierte en el elemento de relación para con el prójimo. ${ }^{31}$

La comunicación que establece el poema es indisociable, por otra parte y como ya lo hemos comprobado, de la búsqueda y la experimentación con el lenguaje. ${ }^{32}$ Su eficacia dependerá del alcance de sus componentes y del impacto que estos generen en los oyentes o lectores. En este sentido, explica la autora uruguaya, el poema secreta «vectores de energía» que llegan lejos «como si hubieran estado a presión dentro del texto». ${ }^{33}$ Esta afirmación, proveniente de su propia experiencia, coincide con la hipótesis desarrollada por Iuri Lotman respecto de la complejidad de la estructura poética, que «permite transmitir un volumen de información completamente inaccesible para su transmisión mediante una estructura elemental propiamente lingüística». ${ }^{34}$ En otras palabras, la poesía resulta un habla condensada, un texto atravesado por múltiples códigos (retóricos, estéticos, ideológicos) que es capaz de despertar emociones fuertes en el receptor: «siento que me recorre el cuerpo un escalofrío que me eriza el pelo. Es cuando la palabra te estremece igual que la fiebre», ${ }^{35}$ confesaba Berenguer en 1988.

La dialéctica concentración/densidad, por un lado, e interpelación/comunicación, por otro, es propia del discurso poético. En su opacidad surgen a veces «zonas transparentes», ${ }^{36}$ y el dispositivo verbal logra que, en medio de un ritmo pautado, sea posible la irrupción de lo sorpresivo. Tomemos en consideración este breve poema perteneciente a la serie Con el tigre entre las cosas. Manual de aventuras domésticas (1986-1994):

El pájaro sobre la última rama

de la hiedra que trepa por el muro,

31 Amanda Berenguer: El monstruo, p. 40.

32 Ibid., p. 40.

33 Ibid., p. 87.

34 Yuri M. Lotman: Estructura del texto artístico. Madrid: Istmo 1982, p. 21.

35 Amanda Berenguer: El monstruo, p. 86.

36 Alicia Genovese: Leer poesía. Lo leve, lo grave, lo opaco. Buenos Aires: FCE 2011, p. 52. 


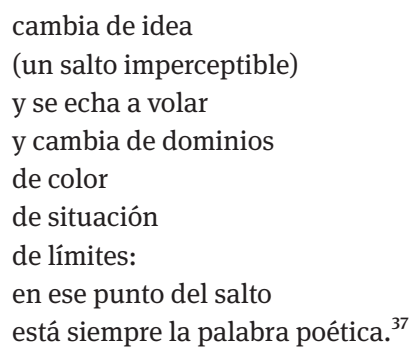

Estos versos perfilan una poesía en precaria quietud, siempre lista para el vuelo, imprevisible y huidiza como el gesto de un pájaro. Insiste Berenguer en que la poesía es «tensora de la vida, [. . .] aventura a todo riesgo, [. . . ] conocimiento revolucionario». ${ }^{38}$ Cargadas con $\mathrm{su}$ «don explosivo», ${ }^{39}$ las imágenes operan como «puentes» ${ }^{40}$ y saltan como «canguros». ${ }^{41}$

La imaginación poética introduce un salto proyectivo, hacia el futuro, pero cumple también una función primordial en el trabajo de la memoria. La recuperación del pasado doloroso y traumático se desgrana en Los signos sobre la mesa (1988), el texto de Berenguer que aborda de manera más explícita la violencia ejercida durante la dictadura cívico-militar uruguaya. Se trata de un poema largo atravesado por preguntas sin respuesta, repeticiones de palabras y sintagmas, versos fraccionados por guiones o paréntesis, grandes zonas de espacio en blanco y cambios del verso a la prosa que evocan el eterno presente de la tortura: ${ }^{42}$

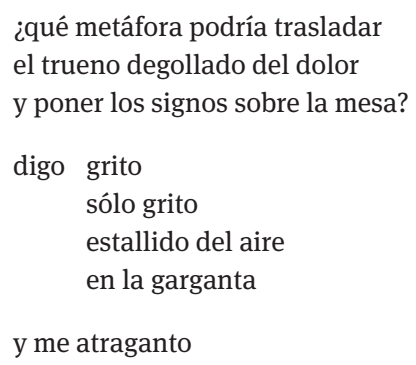

37 Amanda Berenguer: Constelación, p. 567.

38 Amanda Berenguer: El monstruo, p. 85.

39 Ibid., p. 12.

40 Ibid., p. 85.

41 Ibid., p. 69.

42 María Lucía Puppo: «Entre estos muros se tortura»: espacio y memoria en Los signos sobre la mesa (1987) de Amanda Berenguer». In: Cleusa Maria Graebin, Zilá Bernd y Maria Luiza Berwanger da Silva (eds.): Memória social e cidade: prácticas, representaçoes e imaginarios, p. 39-50. Canoas: UNILASALLE, Série Memória e Patrimônio, 2018. 
mientras

con una pequeña brasa

alguien quema los pezones de esa mujer

atada a un muro de terror ${ }^{43}$

El poema está fechado en los inicios de la posdictadura, transcurridos ya los hechos, pero sin embargo la hablante poética elige situarse en tiempo presente, en una posición de testigo. Su mirada y su voz se muestran limitadas, insuficientes, mientras el relato evoca crueldades, perversiones, huesos y rastros de sangre como despojos de una realidad que el discurso oficial pretende esconder. En ese trance la expresión se acerca al aullido y el balbuceo: «La palabra también cae de sus andamios / se descuartiza / y queda inválida en medio de las cosas que pasaron». ${ }^{44}$ Desplegar en todo su dramatismo la impotencia de la palabra para dar cuenta del horror, esa es también una misión de la poesía.

\section{Palabras finales}

Toda indagación acerca del ars poetica de Amanda Berenguer debe concluir que no hay una, sino muchas poéticas que coexisten en su obra. Lo comprobamos tras haber analizado varios poemas y declaraciones de la autora centrados en la temática metatextual, y lo comprobaría también un repaso por las numerosas escenas de escritura que proponen sus textos, donde la poeta aparece sentada entre sus papeles, observándose frente al espejo, cocinando, escuchando radio o admirando el efecto del viento en las plantas de su jardín. La preocupación constante por el espacio, la visualidad y el potencial comunicativo de la poesía son quizás los signos más evidentes de una fascinación por todo lo que existe y, en particular, por la maravilla que implica estar vivos. Como solo lo hacen las y los grandes poetas de nuestro tiempo, la autora uruguaya supo tensionar y dar nuevo dinamismo a la relación que une sujeto, mundo y lenguaje, los tres polos involucrados en el lirismo moderno..$^{45}$

El famoso soneto de Quevedo define al niño Amor como «un andar solitario entre la gente». Podemos afirmar que Berenguer invierte la fórmula quevediana para entender la poesía como una soledad acompañada. Epígrafes, dedicatorias, citas y evocaciones de otros poetas surcan sus textos introduciendo una polifonía

43 Amanda Berenguer: Constelación, p. 533.

44 Ibid., p. 540.

45 Michel Collot: Sujet, monde et langage dans la poésie moderne: de Baudelaire à Ponge. Paris: Classiques Garnier 2018. 
que traspasa los límites de las lenguas, el tiempo y el espacio. En la cadena de predecesores se destacan dos mujeres que ella sitúa en el origen de su genealogía: Emily Dickinson y Delmira Agustini. ${ }^{46}$ Asimismo, científicos y artistas notables como Galileo, Dante, Leonardo da Vinci, Goya o Monet proponen enigmas que la poeta buscará resolver con sus propios métodos. Por otra parte, en tanto artífice de la poesía visual y diseñadora de los collages que funcionan como tapas de sus libros, Berenguer entiende la escritura como un oficio manual lindante con la pintura, el dibujo y el grabado. Hemos advertido, en particular, cómo su poesía ensaya diversos acercamientos a un diálogo ininterrumpido entre la palabra, la fotografía y la imagen cinematográfica.

En una actitud valiente y cómplice con sus receptores/as, Amanda Berenguer ofrenda sus textos sin caer en gestos histriónicos ni consignas solemnes. Ella define en términos muy simples su oficio: «Me gustaría comunicar un trozo del diálogo de un ser humano con su tiempo o más sencillamente parte del balance a pérdidas y ganancias entre una mujer y lo que le acontece». ${ }^{47}$ En ese «balance» se juega la autenticidad de una poesía y una poética que nos interpelan profundamente como lectores/as, invitándonos a repensar nuestros vínculos con los otros, así como el sentido y las metas que elegimos darles a nuestras propias vidas.

\section{Bibliografía}

Bajter, Ignacio: «La casa móvil: Amanda Berenguer ante la traducción». In: Revista de la Biblioteca Nacional 6-7 (2012), p. 199-221.

Berenguer, Amanda: El monstruo incesante (expedición de caza). Montevideo: Arca 1990.

-: Constelación del Navío. Poesía 1950-2002. Montevideo: H Editores 2002.

-: La cuidadora del fuego, compil. Roberto Echavarren. Montevideo: La Flauta Mágica 2010.

Blixen, Carina: «Amanda Berenguer: Poeta en metamorfosis». In: Heber Raviolo y Pablo Rocca (eds.): Historia de la Literatura Uruguaya contemporánea. Tomo II. Una Literatura en movimiento, p. 125-143. Montevideo: Banda Oriental 1997.

Celan, Paul: Obras completas, trad. José Luis Reina Palazón. Madrid: Trotta 2000.

Collot, Michel: Sujet, monde et langage dans la poésie moderne: de Baudelaire à Ponge. Paris: Classiques Garnier 2018.

Courtoisie, Rafael: «Navegar es necesario: Suma poética de Amanda Berenguer». In: El País Cultural 706, 16 de mayo de 2003. http://letras-uruguay.espaciolatino.com/berenguer/ bio.html [Consultado el 15 de septiembre 2020].

46 El rol de Berenguer como traductora de Emily Dickinson, por una parte, y estudiosa de Delmira Agustini, por otra, se analizan respectivamente en Bajter (2012) y Puppo (2019).

47 Amanda Berenguer: El monstruo, p. 101. 
Derrida, Jacques: «Che cos’è la poesia?». In: Poesia I (11 de noviembre de 1988).

Traducción de J. S. Perednik para la Edición digital de Derrida en castellano. http:// www.redaprenderycambiar.com.ar/derrida/textos/poesia.html [Consultado el 15 de septiembre 2020].

García Robles, Hugo: «Constancia de la razón poética». In: Cuadernos Hispanoamericanos 632 (2003), p. 19-28.

Genovese, Alicia: Leer poesía. Lo leve, lo grave, lo opaco. Buenos Aires: FCE 2011.

Lotman, Yuri M.: Estructura del texto artístico. Madrid: Istmo 1982.

Padín, Clemente: «V+V. Lo Verbal y lo Visual en el arte uruguayo. Segunda Parte». In: Escáner Cultural. El Mundo del Arte 20 (2000). http://www.escaner.cl/escaner20/acorreo.html [Consultado el 16 de septiembre 2020].

Puppo, María Lucía: «Contra el fondo negro: autofiguración y poética en dos collages de Amanda Berenguer». In: Actas de las I Jornadas Interdisciplinarias sobre Estudios de Género y Estudios Visuales «La producción visual de la sexualidad». Mar del Plata: Facultad de Humanidades/Universidad Nacional de Mar del Plata 2014. CD Rom.

-: «Teoría y práctica de la poesía cinética en Composición de lugar (1976) de Amanda Berenguer». In: LETRAS: Revista de la Facultad de Filosofía y Letras de la Pontificia Universidad Católica Argentina 69-70 (2014), p. 79-100.

-: «Poesía «concéntrica y excéntrica»: notas para leer La botella verde (1995) de Amanda Berenguer». In: Germán Prósperi (ed.): Debates actuales del hispanismo: balances y desafíos críticos: Actas del X Congreso Argentino de Hispanistas, p. 530-539. Santa Fe: Universidad Nacional del Litoral/Facultad de Humanidades y Ciencias 2016.

-: «Dos raras de la poesía uruguaya: Amanda Berenguer y Marosa di Giorgio». In: Ínsula, Revista de Letras y Ciencias Humanas 853-854 (2018), p. 44-47.

-: «Entre la mirada fotográfica y la imagen fantasma: tres autorretratos de Amanda Berenguer». In: Perífrasis: Revista de Literatura, Teoría y Crítica 18 (2018), p. 65-79.

-: «Entre estos muros se tortura»: espacio y memoria en Los signos sobre la mesa (1987) de Amanda Berenguer». In: Cleusa Maria Graebin, Zilá Bernd y Maria Luiza Berwanger da Silva (eds.): Memória social e cidade: práticas, representações e imaginarios, p. 39-50. Canoas: UNILASALLE, Série Memória e Patrimônio, 2018.

-: «¿Dos ojos de animal sombrío»: apropiaciones de la poética y la figura de Delmira Agustini en la poesía de Amanda Berenguer». In: Boletín de Literatura Comparada XLIII (2019), p. 107-122.

Silva Vila, María Inés: Cuarenta y cinco por uno. Montevideo: Fin de Siglo 1993.

Urli, Sebastián: «Entre el gajo y la lengua: Berenguer y los límites del sujeto». In: Revista Iberoamericana 258 (2017), p. 135-153. 